\title{
Measuring Inundation Depth in a Subway Station Using the Laser Image Analysis Method
}

\author{
Inhwan Park ${ }^{1}$, Hoje Seong ${ }^{1}$, Yonguk Ryu ${ }^{2}$ and Dong Sop Rhee ${ }^{1, *}$ \\ 1 Korea Institute of Civil Engineering and Building Technology, 283 Goyangdae-Ro, Ilsanseo-Gu, \\ Goyang-Si 10223, Gyeonggi-Do, Korea; inhwanpark@kict.re.kr (I.P.); hoje.seong@kict.re.kr (H.S.) \\ 2 Ocean Engineering Department, Pukyong National University, Busan 48513, Korea; yuryu@pknu.ac.kr \\ * Correspondence: dsrhee@kict.re.kr; Tel.: +82-31-910-0396
}

Received: 21 September 2018; Accepted: 28 October 2018; Published: 1 November 2018

\begin{abstract}
Subway station platforms are vulnerable to flood damage. Thus, investigation of inundation properties in subway platforms is required to ensure the safety of citizens against flooding. In this study, the evacuation time and safety were analyzed in a subway station model using inundation depth measurements. The subway station model contained shallow water depth conditions, which did not allow for contact-type measurement devices. Instead, an image analysis procedure using laser images was proposed to measure the inundation depth. The proposed laser image analysis method can recognize a boundary line between the water and air by visualizing the water surface using a laser sheet. The inundation depth measurements using the image analysis method were reasonably accurate, resulting in differences of $2.97-7.67 \%$ compared to the results obtained using a digital point gauge. When inflow positions and flowrates of rainwater were changed, the measured results showed that the inundation depth increased in areas in which the rainwater inflow was relatively small or collided when moving in the direction opposite to the rainwater. The calculated evacuation time from the subway station showed that a drainage system is required to decrease the inundation depth in areas of inflowing rainwater collision. Furthermore, the estimated results of evacuation safety showed that safety handles are necessary even in low depth regions to prevent people from falling down due to increased flow velocity, during evacuation.
\end{abstract}

Keywords: urban flood; inundation depth; laser image analysis; evacuation time

\section{Introduction}

Urban flood damage is increasing owing to climate change and urban development. Underground spaces, such as shopping malls and subway stations, are especially vulnerable to inundation in the event of a flood. The Gangnam subway station in South Korea was inundated with water due to torrential rain in 2011. In 2014 and 2017, the subway platforms in Busan were inundated by rainwater. These events showed that considerable efforts are required to prevent the inundation of underground spaces. In particular, for subway stations used by many people in urban areas, it is necessary to measure the inundation depth to establish evacuation routes in case of a flood.

Studies have been conducted to assess the risks to underground spaces in the case of a flood. Ishigaki et al. [1] calculated the specific force caused by rainwater when it entered a staircase leading to an underground station. They proposed evacuation routes in case of underground flooding; however, they analyzed the inundation depth calculated by two-dimensional (2D) numerical simulation owing to difficulties in real measurements. Shao [2] analyzed the relationship between rainfall intensity and underground space inundation depth and proposed criteria for underground space design. Later, Joo and Kim [3] performed evacuation simulation experiments considering various inundation situations and proposed safety criteria for staircases leading to underground spaces. Kim et al. [4] 
developed the adaptive transfer method to consider inundation properties in an underground space using a 2D flow analysis model. Previous studies mainly focused on staircases leading to underground spaces to analyze the inundation risks associated with underground spaces; however, it is also necessary to measure the spatial changes in the inundation depth to establish evacuation routes in underground spaces.

Most studies use contact-type ultrasonic instruments to measure hydraulic data. An acoustic doppler current profiler (ADCP) measures flow velocity and water depth through the waves reflected by the bottom of a river. However, as suggested by Shao [2], it is difficult to use measuring instruments, such as ADCP, to measure the inundation depth in urban areas because the inundation depth is approximately $0.2 \mathrm{~m}$ or less at a rainfall intensity of less than $70 \mathrm{~mm} / \mathrm{h}$. Therefore, it is necessary to develop a non-contact measurement method capable of measuring water depth at low velocities as well as in complicated structures. Takagi [5] proposed a method for measuring water level using the images of a stick ruler instead of using sensors. Nguyen et al. [6] used an image analysis method to measure the water level in a sewer by capturing images of a stage gauge using a closed circuit television (CCTV). Later, the water level measurement method using CCTV images was used as a means of remote surveillance in river environments (Kim et al. [7]; Kim et al. [8]). Furthermore, Zhang et al. [9] proposed a new stage gauge design to improve the accuracy of image analysis. In the research field of pattern recognition, the geodesic distance method has been reported as a new method, in which a boundary line between two mediums can be detected by using the exponential function [10]. It is possible to more easily visualize the movement of water using a laser compared to using only a camera. Thus, flow measurement methods using a laser, including laser doppler velocimetry (LDV), particle tracking velocimetry (PTV), and particle image velocimetry (PIV) methods, are representative technologies using image analysis technology (Aberle et al. [11]). Therefore, Voulgaropoulos and Angeli [12] proposed a method for measuring flow inside a duct through image analysis using laser images. It is possible to capture images focused on the area required for analysis when a laser is used, resulting in an easier analysis of the images.

In this study, the inundation depth inside a subway station model was measured using a non-contact water depth calculation method. For non-contact water depth calculation, laser images were captured, and the water depth was calculated through image processing. From the water depth measurements, spatial changes in the inundation depth were analyzed according to the changes in the inflow points and flowrates. In addition, risks due to the underground subway station inundation were analyzed through calculation of the evacuation time change and specific force according to the inundation depth and flow velocity.

\section{Water Depth Measurement Using the Image Processing Method}

\subsection{Descriptions of Experiment Methods}

The underground subway station model used for the inundation depth measurements is shown in Figure 1. The experimental model was designed through an analysis of the specifications of a typical subway platform, and the model was scaled down to $1 / 20$ of the actual platform. The model consists of staircases from the ground to B1F, staircases to B2F, and a flow supply device to simulate the rainwater inflow. The plan view of the model is shown in Figure 2. The width of the model was $0.5 \mathrm{~m}$ and the length was $2.0 \mathrm{~m}$. The width of the staircases to B1F was $0.1 \mathrm{~m}$ and that of the staircases to B2F was $0.2 \mathrm{~m}$. In this model, the rainwater from roads of urban area was assumed to flow in directly through the staircases because most subway station entrances are directly connected to the ground level. The rainwater introduced into $\mathrm{B} 1 \mathrm{~F}$ was controlled through the flow adjustment value, and it was possible to determine the inflow points (P1, P2, P3, and P4) through valve adjustment. Thus, the inundation depth was changed according to the inflow points and flow rate. The green lines in Figure 2 indicate the measurement sections (Sec. A, Sec. B, and Sec. C), which were determined to analyze inundation properties of the subway station model. At each line, inundation depth was 
measured using the laser image analysis algorithm. From the inundation depth measurements, evacuation safety was estimated by using the evacuation time and specific force.

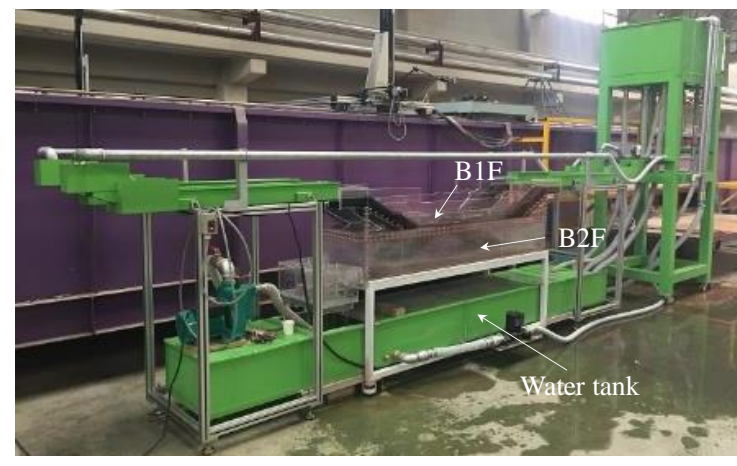

(a)

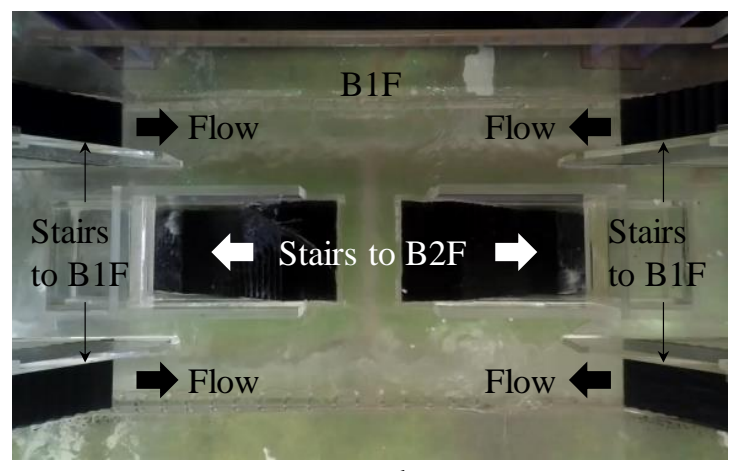

(b)

Figure 1. Subway station model for inundation experiments: (a) Experiment channel; (b) Plan view of B1F.

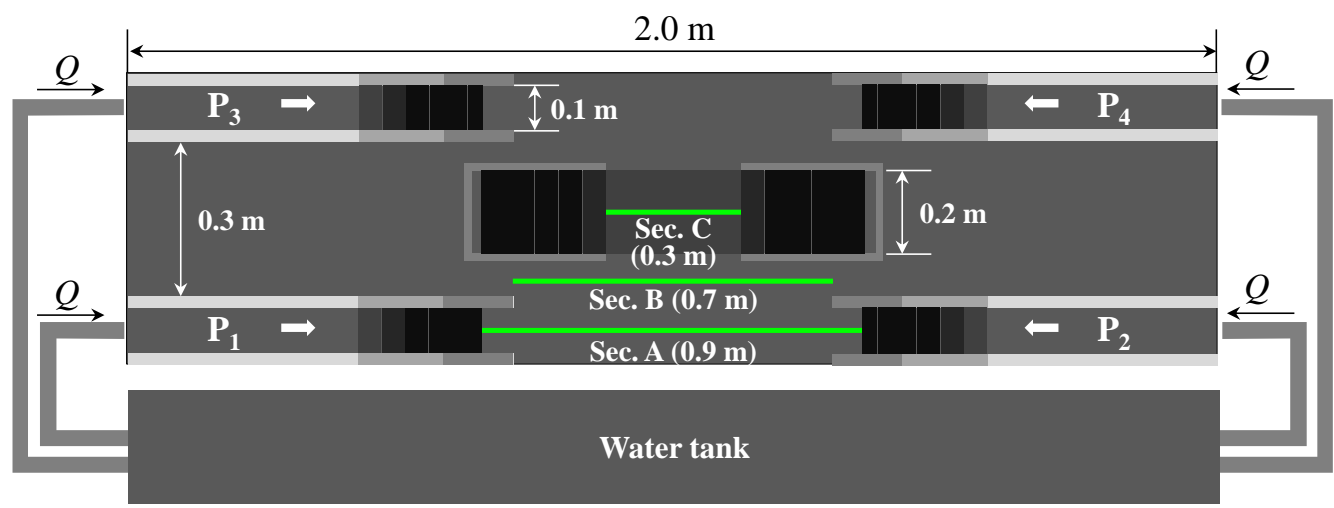

Figure 2. Plan view of the subway station model.

To reduce damage to humans from the flooding of underground spaces, it is necessary to calculate the time required for evacuation in case of inundation and prepare evacuation routes [1]. According to the Committee of Countermeasures against Inundation Disasters in Underground Spaces (CCIDUS) [13], the time required for evacuating a person from underground spaces is:

$$
t_{e v}=\frac{60 l}{v_{u}\left(1-h_{u} / 0.7\right)}
$$

where $t_{e v}$ is the underground evacuation interval; $v_{u}=60 \mathrm{~m} / \mathrm{min} ; h_{u}$ is the inundation depth in the underground floor $(\mathrm{m})$; and $l$ is the distance from the farthest location in the underground space to the underground entrance of the staircase $(\mathrm{m})$. From $t_{e v}$, it would be possible to determine how fast a person should escape from the subway station. Furthermore, it is also important to notice which route is safer to evacuate. The aforementioned evacuation safety can be estimated from the specific force $\left(M_{0}\right)$, which has been suggested as the criterion to evaluate the safety of a person [1]. The specific force is calculated using the flow velocity and the inundation depth as follows.

$$
M_{0}=\frac{u^{2} h_{u}}{g}+\frac{h_{u}^{2}}{2}
$$

where $u$ is the flow velocity and $g$ is the gravity acceleration. Ishigaki et al. [1] reported that normal males can safely escape from an underground space if $M_{0}<0.125$. To calculate Equation (2), the flow 
velocity was measured using the large scale particle image velocimetry (LSPIV) method. LSPIV was adopted because the flow depth was not sufficient for use of a contact type measurement device.

\subsection{Development of the Algorithm}

In this study, an image analysis method was used instead of contact-type measuring instruments to measure the inundation depth inside the subway station platform model in a flood. The experimental setting used for the image analysis method is shown in Figure 3, in which the laser sheet and floating particles were used to make the pixel value at the water surface be the local maximum. The laser sheet formed on the water surface was used to take an ortho-image, which is an image without distortion of relative distance, of the inundation cross section using a digital camera as shown in Figure $3 \mathrm{~b}$. To spread the laser sheet to the water surface in a vertical direction, the reflection angle was adjusted using the mirror, as shown in Figure 3. The light intensity of the laser sheet was the brightest on the water surface and then gradually decreased in the water. Therefore, to clearly recognize the water surface, light-reflecting particles were spread so that the highest intensity light could be generated on the water surface.

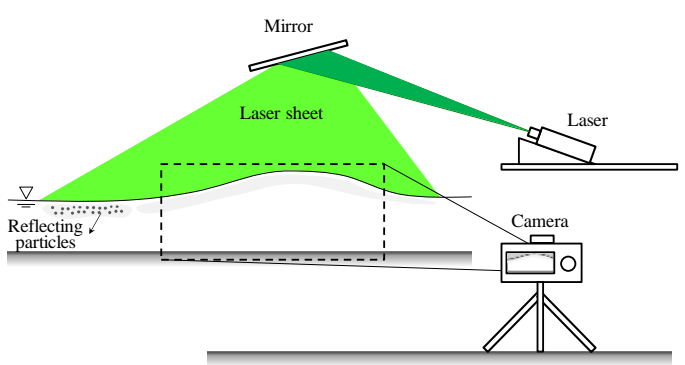

(a)

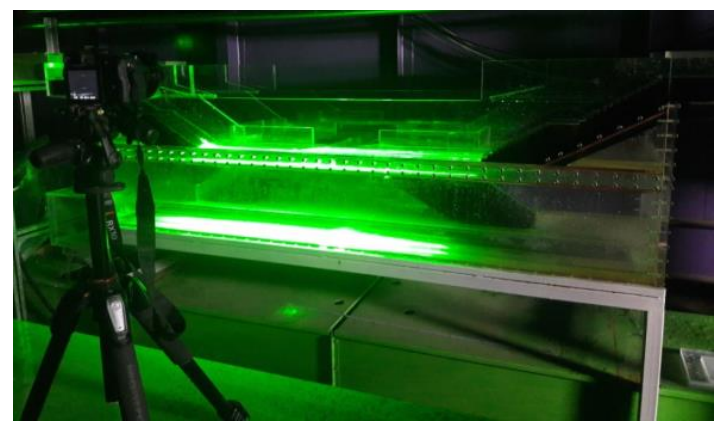

(b)

Figure 3. Inundation depth measurements using the laser image: (a) Outlines of water surface measurements using a laser; (b) Photo of water surface measurements.

Previous researchers proposed the Hough transform [6] and correlation coefficients between image frames [14] to analyze the water level from the captured images. However, these methods were not enough to reflect fluctuations in the water surface caused by water waves [6]. Therefore, it is difficult to apply the existing method to the underground subway station model, in which the shape of the water surface rapidly changes over time due to the influence of the water waves generated by staircases. In this study, laser images capable of clearly expressing sudden changes in the water surface inside the underground subway station model were used, and an image analysis algorithm was developed and used to analyze water depth inside the subway station. The water depth measurement algorithm that uses laser images is shown in Figure 4. First, an image captured by the camera was divided into several images and read by software. To filter out noise in an instantaneous image, the time-average technique was adopted. The time-average method shown in Equation (3) is a general method used to mitigate bias from fluctuating motion [15].

$$
\bar{p}(i, j)=\frac{1}{T} \int_{0}^{T} p(i, j, t) d t
$$

where $T$ is the recording time, $p$ is the pixel value of the instantaneously captured image, $(i, j)$ are the coordinates of each pixel, and $\bar{p}$ is the pixel value of the time-averaged image. Figure 4 is a graph showing both the time series of pixel values $(p(i, j))$ and the time-averaged values $(\bar{p}(i, j))$ at a position on the water surface. In an image, the pixel value of the brightest point was 255 and that of the darkest point was zero. The $y$-axis in Figure 5 normalized the pixel value using the maximum value, i.e., 255. 
Figure 5 shows that the variation in the pixel value gradually converges over time. Therefore, the pixel value for the $(i, j)$ coordinates of the time-averaged image is stored in an $(N \times M)$ matrix.

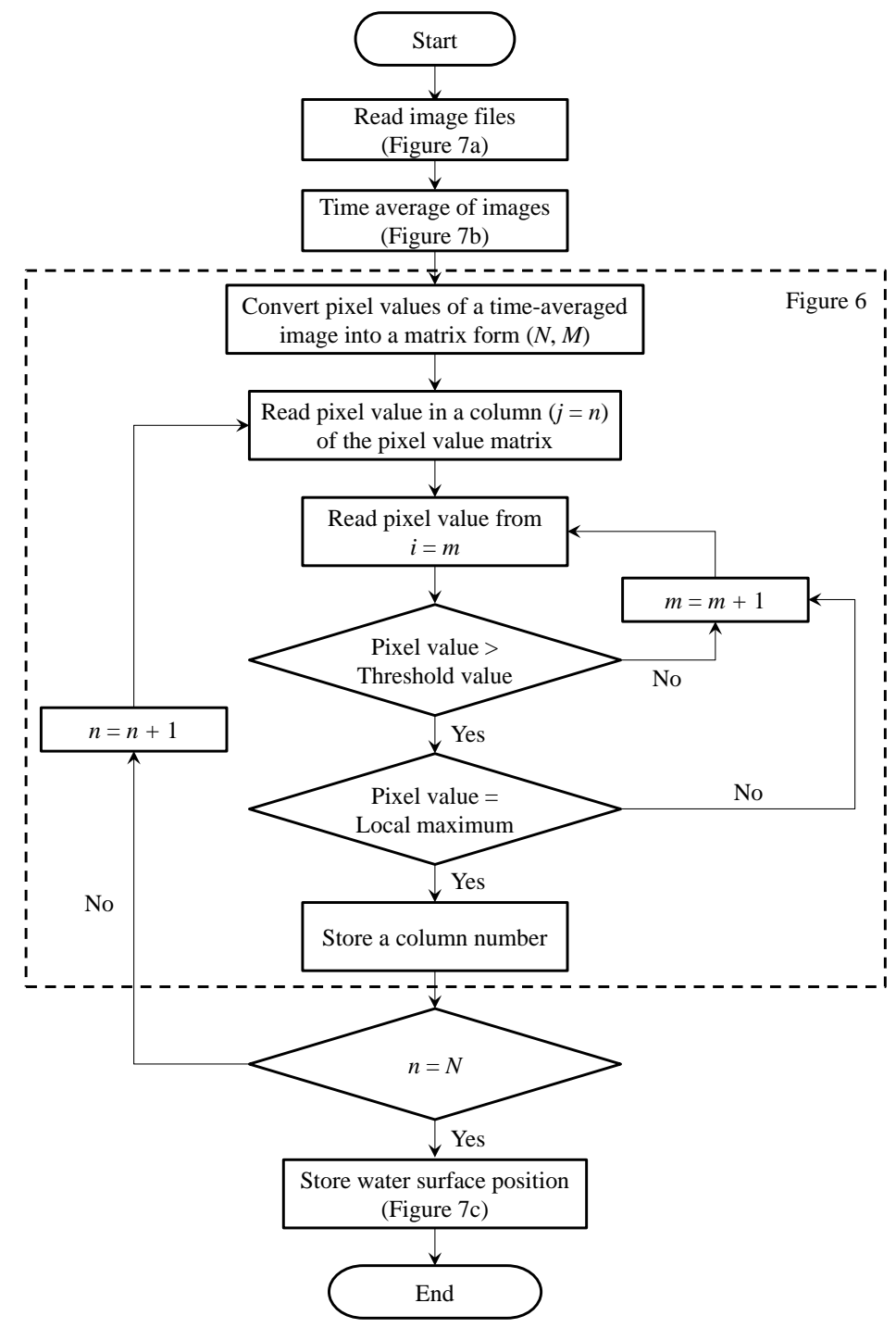

Figure 4. An algorithm for calculation of inundation depth from the laser image.

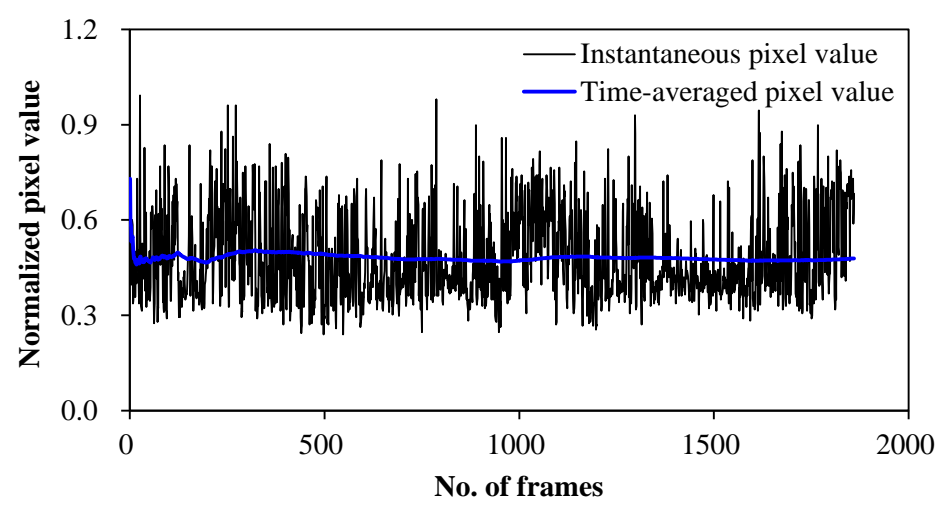

Figure 5. Time series of pixel values at a position of water surface.

To separate the water surface from the pixel information stored in the matrix, the pixel information of each column vector was read. For laser images, as the light source entered from the top of the water as shown in Figure 3, the strongest light reflected from the water surface due to the injected particles, 
and it was converted into the highest pixel value for each column vector. Therefore, the pixel value of each column vector gradually increased around the water surface and decreased after the pixel passed through the water surface. According to these characteristics of laser images, the row number, $i$, for which the pixel value of the column vector had the same value as the local maximum, was stored as the pixel position of the water surface. Equation (4) was used to find the local maximum value of the pixel value.

$$
\frac{\partial}{\partial i} \bar{p}(i, j)=0
$$

The denominator of Equation (4) indicates a pixel size, which ranged from 0.29-0.53 $\mathrm{mm}$ in this study, and pixel size depended on the resolution of the digital camera and distance from the measurement section. Thus, the precision of water surface detection depends on the pixel size of an image. Through the iterative calculation process, row numbers corresponding to the water surface were determined at each column vector of the matrix, and the water surface positions in the image were extracted. Figure 6 shows the results of analyzing the column vectors of the time-averaged image matrix in accordance with the algorithm in Figure 4. The $y$-axis in Figure 6 is the number of the column vector and represents the $i$-index of the matrix. A larger $i$-index refers to the lower part of the image. As the light was reflected by the water surface, the pixel value was low over the water surface and gradually increased near the water surface due to the influence of the light reflected by the water surface. The pixel value dramatically increased on the water surface due to the floating particles, and the positions where the pixel values showed the local maximum values according to Equation (4) were selected as the water surface. In addition, the water surface could be distinguished because the light intensity gradually decreased in the lower part of the image, as shown in Figure 6. The positions of the water surface were determined as the $i$-index of the pixel of the water surface where $i=71$ in Figure $6 \mathrm{a}$ and $i=73$ in Figure $6 \mathrm{~b}$. After the positions of the water surface were determined, the water depth was calculated using Equation (5).

$$
h=\left(i_{s}-i_{b}\right) \delta_{z}
$$

where $h$ is the water depth, $i_{s}$ is the pixel number of the water surface, $i_{b}$ is the pixel number of the bottom, and $\delta_{z}$ is the scale of a pixel size in the vertical direction.

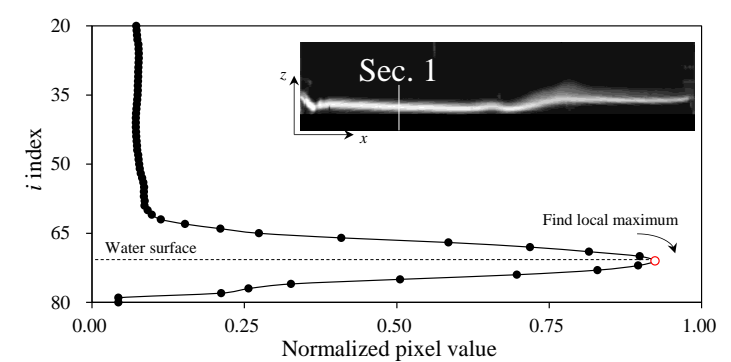

(a)

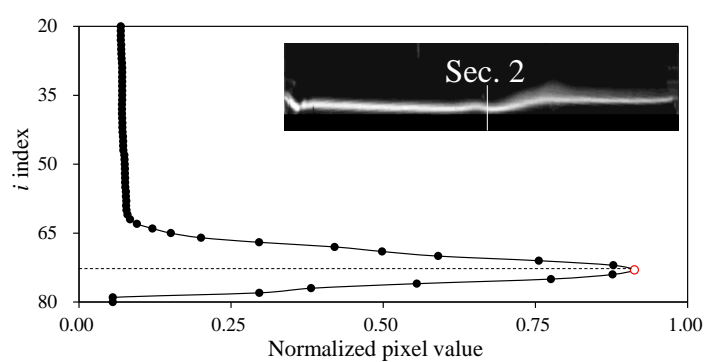

(b)

Figure 6. Inundation depth measurements using the laser image: (a) Sec. 1; (b) Sec. 2.

Figure 7 shows the water depth determination procedure according to the algorithm in Figure 4, using images captured in Sec. A. Figure 7a shows the instantaneous image. The water surface exhibited a bright light from the reflected laser, and two bright layers were visible from the reflection of the acrylic wall. As the instantaneous image exhibited large fluctuations in the water surface, shown in the figure, a water surface close to a straight line was expressed using the time-averaged image, as shown in Figure $7 \mathrm{~b}$. The pixel values from Figure $7 \mathrm{~b}$ were stored in matrix form and converted to pixel values as shown in Figure 6a. When the position of the water surface was determined at each location, the pixels of the water surface could be extracted, as shown in Figure 7c. 


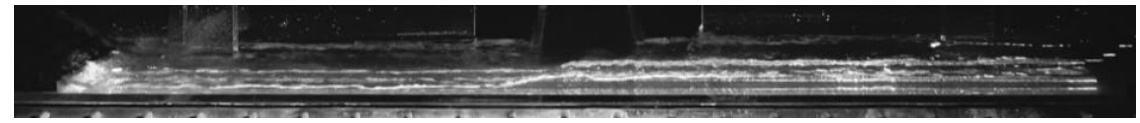

(a)

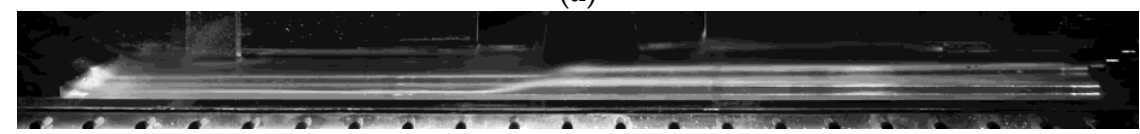

(b)

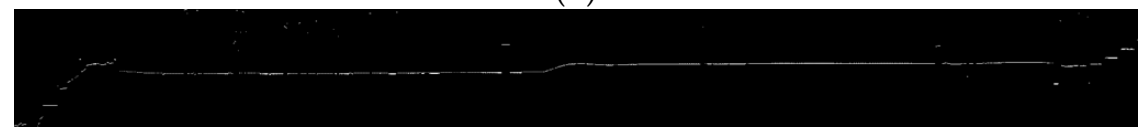

(c)

Figure 7. Inundation depth measurements using the laser image (Sec. A): (a) Instantaneous image;

(b) Time-averaged image; (c) Extracted water surface elevation.

\subsection{Verification of Inundation Depth Measurements}

To verify the water depth obtained through the analysis of laser images, the value was compared with the water depth measured from the experiment channel. A scenario in which flow $\left(Q=3.78 \times 10^{-4} \mathrm{~m}^{3} / \mathrm{s}\right)$ entered from all four staircases had sufficient water depth to allow the use of the digital point gauge. The measurement results of water depth were compared using both the image analysis method and the digital point gauge (KENEK PH-340, C \& V, Gyeonggi-do, Korea), which had an accuracy of $\pm 0.04 \mathrm{~mm}$. The inundation depth was measured under the conditions that rainwater flowed in from all staircases to secure sufficient water depth for using the water-level gauge. The measurements were carried out at three sections, as shown in Figure 2, and the comparison results were plotted in Figure 8. The image analysis method recognized the bubbles, which occurred from the fallen water from the staircases at the left side of Sec. A, as shown in Figure 8a, as the water surface. Conversely, the water level gauge read the water depth under the bubbles. These differences caused measurement errors when using the image analysis method, and the mean absolute percentage error was $7.67 \%$. For Sec. B and Sec. C, the results using the image analysis method showed similar distributions to the measurements using the digital point gauge. Especially in Sec. C, the curvature of the water surface caused by the staircases to B2F was well reflected in both measurement methods. Thus, the error compared to the measurements using the digital point gauge was $2.97 \%$ for Sec C. These results indicated that the water depth analysis results using the laser images accurately represent the actual water depth changes.

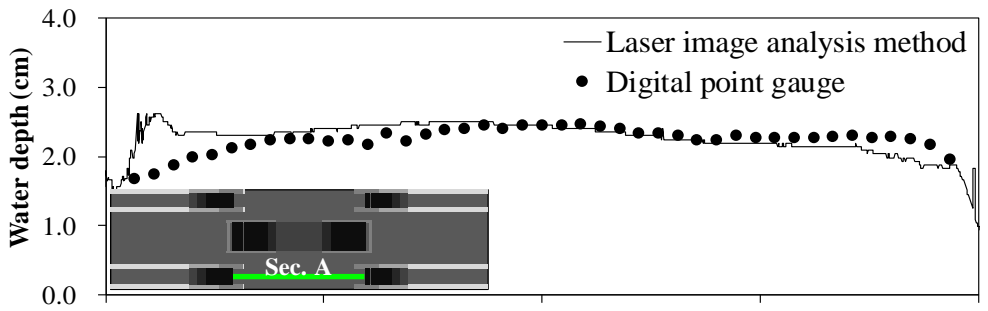

(a)

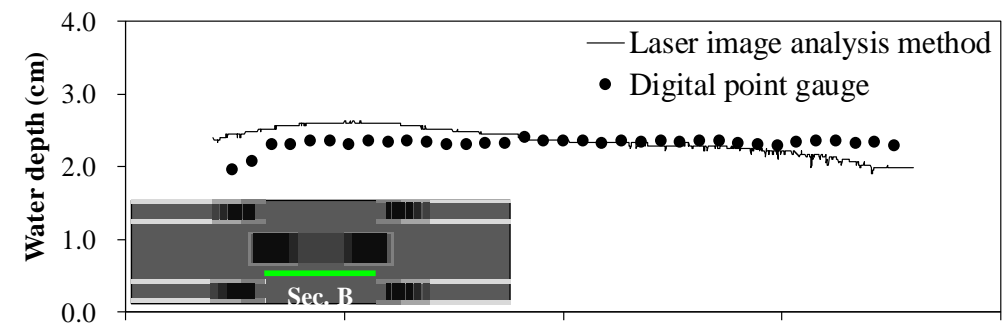

(b)

Figure 8. Cont. 


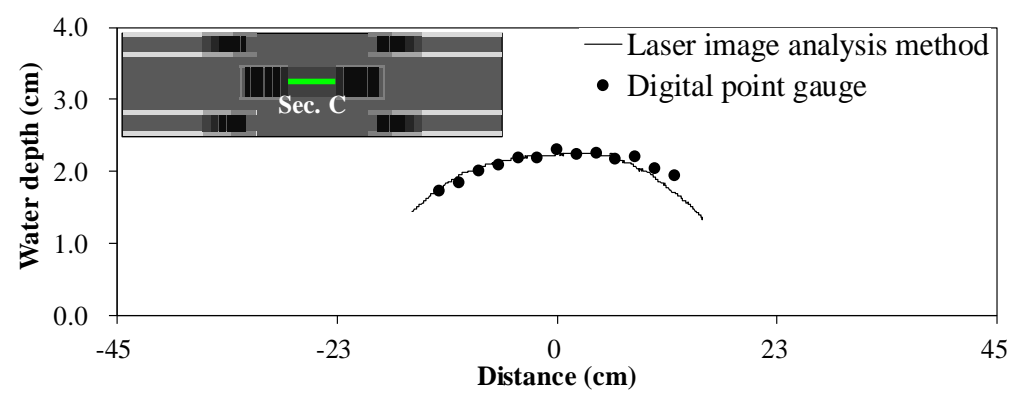

(c)

Figure 8. Comparison between water depth calculation results and measurements: (a) Sec. A; (b) Sec. B; (c) Sec. C.

\section{Inundation Depth in the Subway Station}

The inundation depth measurements were carried out using the aforementioned laser image analysis method. Laser images were captured using the SONY RX10II digital camera (Sony Corporation, Tokyo, Japan). Images captured for $15 \mathrm{~s}$ at 60 frames per second were time-averaged and used for the analysis. As the experiment was performed under the assumption of a steady state, i.e., changes in the inundation depth do not vary over time, the capture of laser images began when changes in the water depth were stabilized after rainwater introduction.

\subsection{Depth Change by the Inflow Positions}

The inundation depth of subway station platform (B1F) was measured assuming a scenario in which rainwater flowed into the staircases. The rainwater inflow points were set as given in Table 1 , and the experiment was performed by varying inflow points and flowrates. The flowrates listed in Table 1 were determined based on the experimental results using the rainfall simulator, in which the flowrate near the entrance of the Sadang subway station located in Seoul, South Korea was in the

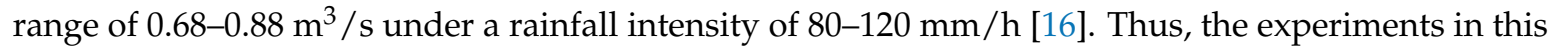
study were carried out in conditions of $Q=3.78 \times 10^{-4} \mathrm{~m}^{3} / \mathrm{s}$ and $Q=4.92 \times 10^{-4} \mathrm{~m}^{3} / \mathrm{s}$ considering the Froude similitude. Figure 9 shows comparisons of the inundation depth according to the rainwater inflow positions. The point where the distance is zero indicates the center of the experiment channel. From the experiment results, when rainwater was introduced to the P3 staircase, which was located at the diagonal position, the inundation depth of Sec. C increased. When additional water flow occurred at the P2 staircase, located at the opposite position of the P1 staircase, the water depth increased in the center of Sec. A, and the maximum water depth in the center increased by approximately $30.4 \%$. The water depth was approximately $82.1 \%$ higher than that for Case P1Q1 and 34.9\% higher than that of Case P12Q1 on average. For Case P123Q1, the water depth of Sec. C was 63\% higher than that of Case P12Q1, and the water depth on the left side of Sec. B was 271.5\% higher than that of Case P13Q1.

When the same flow rate was introduced to all the inflow points, changes in the water depth were similar even though the flow rates increased. Figure 10 shows graphs displaying changes in the water depth for two flow rates. For Cases P1Q1 and P12Q1, inundation depths in Sec. B and Sec. C tended to rise with increasing flowrate, and spatial changes of inundation depths showed similar patterns. For Sec. A of Case P1Q2, the water depth rise section moved to the right by $9 \mathrm{~cm}$ compared to Case P1Q1, due to the water pushing the right side further with the flowrate increase. In Case P1Q2, the pushed water propagated to ambient space and the inundation depth of the right side was maintained at about $1.71 \mathrm{~cm}$, similar to Case P1Q1. 
Table 1. Experimental conditions by flow inlet positions.

\begin{tabular}{ccccc}
\hline \multirow{2}{*}{ Case } & \multicolumn{4}{c}{$Q\left(\mathrm{~m}^{3} / \mathbf{s}\right)$} \\
\cline { 2 - 5 } & $\mathbf{P 1}$ & $\mathbf{P 2}$ & $\mathbf{P 3}$ & $\mathbf{P 4}$ \\
\hline P1Q1 & $3.78 \times 10^{-4}$ & - & - & - \\
P12Q1 & $3.78 \times 10^{-4}$ & $3.78 \times 10^{-4}$ & - & - \\
P13Q1 & $3.78 \times 10^{-4}$ & - & $3.78 \times 10^{-4}$ & - \\
P14Q1 & $3.78 \times 10^{-4}$ & - & - & $3.78 \times 10^{-4}$ \\
P123Q1 & $3.78 \times 10^{-4}$ & $3.78 \times 10^{-4}$ & $3.78 \times 10^{-4}$ & - \\
P1234Q1 & $3.78 \times 10^{-4}$ & $3.78 \times 10^{-4}$ & $3.78 \times 10^{-4}$ & $3.78 \times 10^{-4}$ \\
\hline P1Q2 & $4.92 \times 10^{-4}$ & - & - & - \\
P12Q2 & $4.92 \times 10^{-4}$ & $4.92 \times 10^{-4}$ & - & - \\
P13Q2 & $4.92 \times 10^{-4}$ & - & $4.92 \times 10^{-4}$ & - \\
P14Q2 & $4.92 \times 10^{-4}$ & - & - & $4.92 \times 10^{-4}$ \\
P123Q2 & $4.92 \times 10^{-4}$ & $4.92 \times 10^{-4}$ & $4.92 \times 10^{-4}$ & - \\
P1234Q2 & $4.92 \times 10^{-4}$ & $4.92 \times 10^{-4}$ & $4.92 \times 10^{-4}$ & $4.92 \times 10^{-4}$ \\
\hline
\end{tabular}
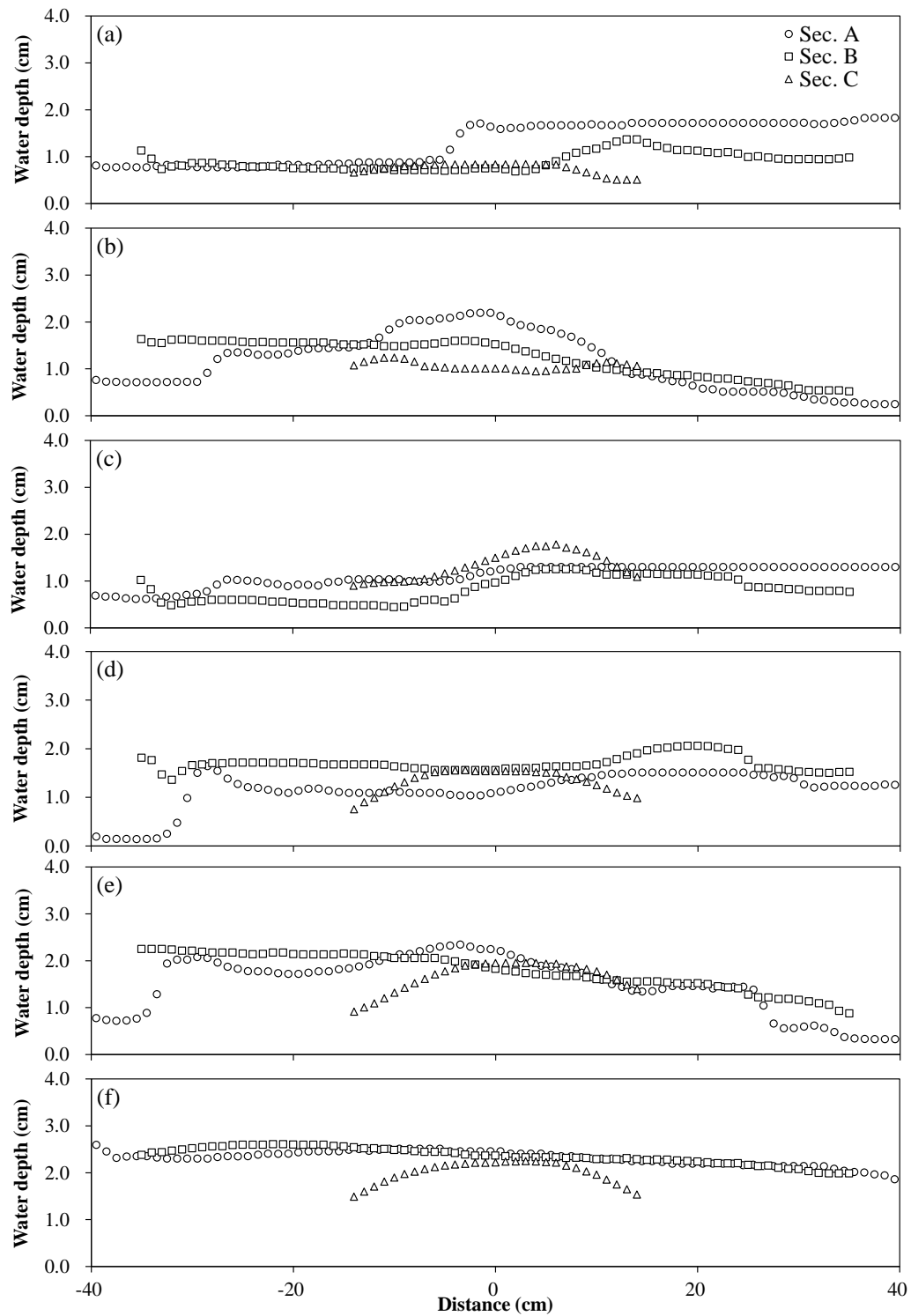

Figure 9. Comparison of the inundation depth by changing the inflow position: (a) Case P1Q1; (b) Case P12Q1; (c) Case P13Q1; (d) Case P14Q1; (e) Case P123Q1; (f) Case P1234Q1. 


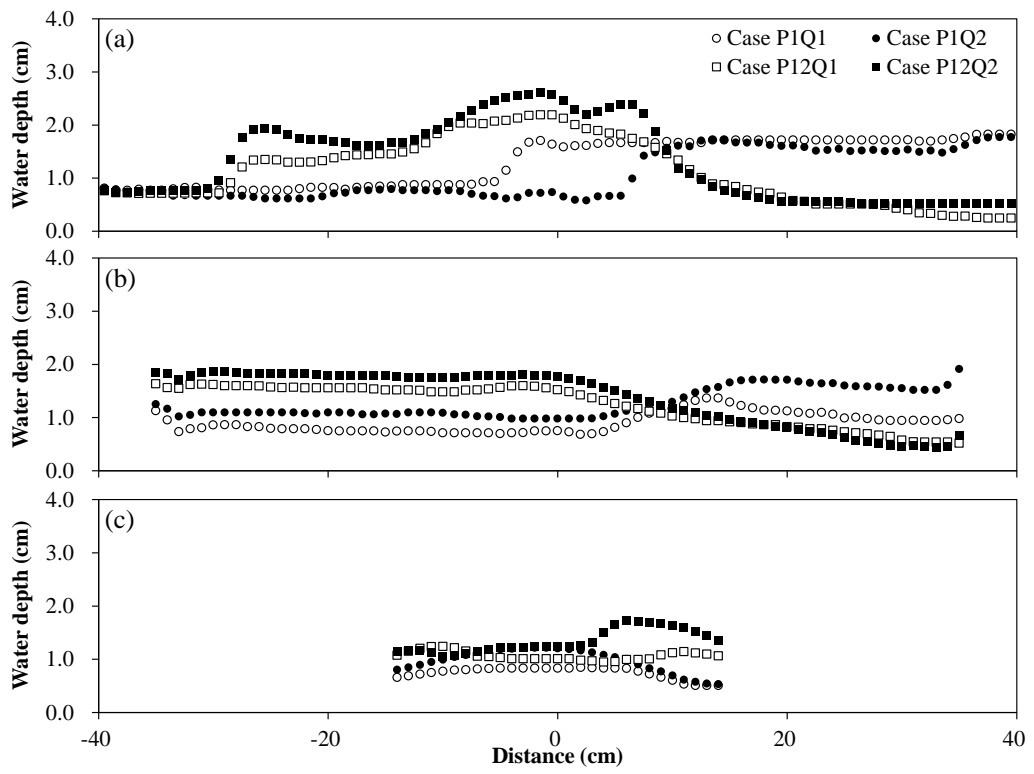

Figure 10. Comparison of the inundation depth by changing flowrate: (a) Sec. A; (b) Sec. B; (c) Sec. C.

\subsection{Depth Change by the Non-Uniformly Distributed Flowrate}

The elevation variations near the subway station entrance could cause varied rainwater inflow at each entrance. Thus, changes in the inundation depth were analyzed with the assumption that non-uniform flow rates were introduced to each staircase, and results were compared to the uniformly distributed cases. The flow rates introduced to each staircase were set as shown in Table 2 . Figure 11 shows the comparison of the inundation depth when non-uniform flow rates were introduced under the conditions specified in Table 2. For Case P12Q1, the inundation depth in the center of Sec. A increased because the same flow rates were introduced to the left and right staircases, as shown in Figure 9b. On the other hand, for Case P1Q1P2Q2, the position of the water depth increase moved to the left of the center because more rainwater was introduced to P2. For Sec. B, changes in the water depth were similar for Cases P12Q1 and P1Q1P2Q2, but the water depth on the left increased by $45 \%$ due to the flowrate increase at P2. In addition, for Sec. C, the water depth increased by approximately $24 \%$ on average. Case P13Q1P24Q2 assumed that the flow rates introduced to the P2 and P4 staircases, which were located on the right, were higher than those introduced to the P1 and P3 staircases. From the results, the inundation depth increased in the section $x=0.0-28.5 \mathrm{~cm}$, and thus the inundation depth exhibited a stepwise distribution.

Case P1Q1P3Q2 represented changes in the inundation depth when a higher flow rate was introduced to P3, located at the diagonal position. Compared to Figure 9c where uniform flow rates were introduced, the water depth rise sections expanded to the left in both Sec. A and Sec. C. In particular, in Sec. B, the inundation depth drastically increased to be approximately 2.2 times higher than in Case P13Q1. These results showed that a drainage system is necessary to mitigate the inundation depth in Sec. B when the diagonal entrance had higher rainwater inflow.

Table 2. Experimental conditions by inlet flowrates.

\begin{tabular}{ccccc}
\hline \multirow{2}{*}{ Case } & \multicolumn{4}{c}{$Q\left(\mathbf{m}^{3} / \mathbf{s}\right)$} \\
\cline { 2 - 5 } & P1 & P2 & P3 & P4 \\
\hline P1Q1P2Q2 & $3.78 \times 10^{-4}$ & $4.92 \times 10^{-4}$ & - & - \\
P1Q1P3Q2 & $3.78 \times 10^{-4}$ & - & $4.92 \times 10^{-4}$ & - \\
P13Q1P24Q2 & $3.78 \times 10^{-4}$ & $4.92 \times 10^{-4}$ & $3.78 \times 10^{-4}$ & $4.92 \times 10^{-4}$ \\
\hline
\end{tabular}




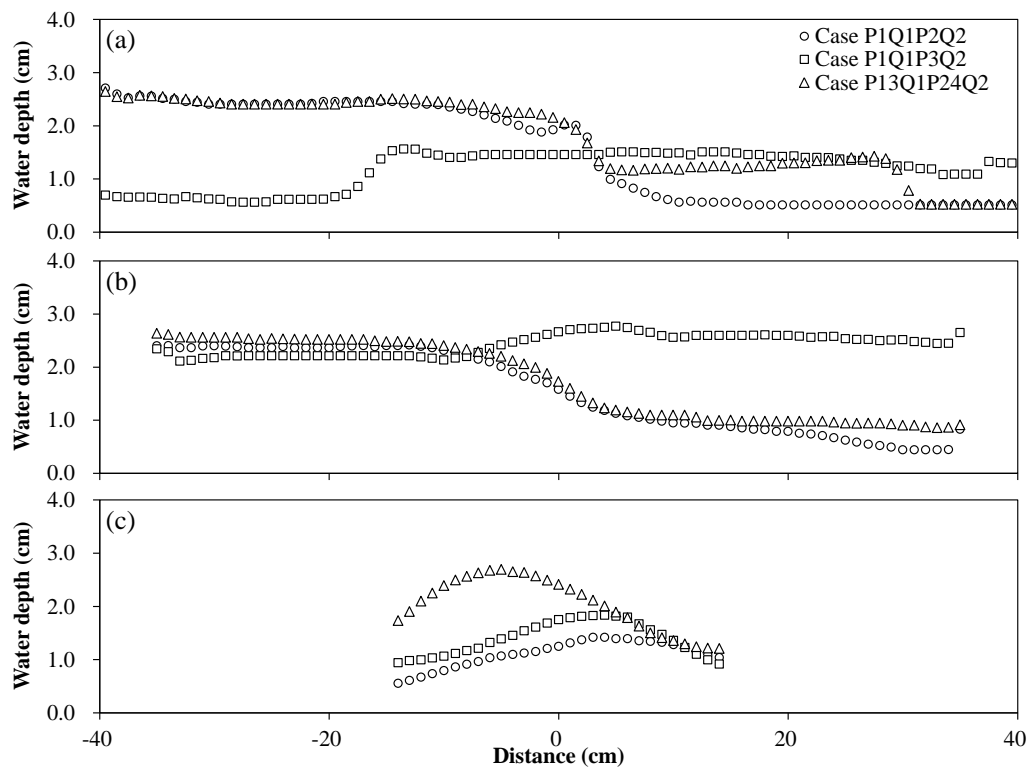

Figure 11. Inundation depth changes with non-uniform inflows: (a) Sec. A; (b) Sec. B; (c) Sec. C.

\section{Evacuation Time from the Underground Space}

The time required for evacuating a person from the subway station was calculated using Equation (1). The real scale inundation depth in Equation (1) was adopted from the measurements in Figure 9. Figure 12 shows spatial changes in the evacuation time from Sec. A to Sec. C. As the exits for evacuation were located on both sides of Sec. A, the evacuation distance of the person located in the center of Sec. $C$ was the farthest $(l=14.2 \mathrm{~m})$. Therefore, the evacuation time $\left(t_{e v}\right)$ from Sec. $\mathrm{C}$ was calculated to be longer than those from other sections in most cases, and $t_{e v}$ decreased close to exits. Furthermore, $t_{e v}$ in Sec. C gradually increased as the number of rainwater inflow positions increased, and the area that required the most evacuation time was expanded for Case P1234Q1, in which $t_{e v}$ from Sec. C took about two times longer than in Case P1Q1. For Cases P12Q1 and P123Q1, however, $t_{e v}$ increased near the center of Sec. A even though the exits were closer than Sec. B. As shown in Figure 9, the water depth at the center of Sec. A increased due to collision of inflowing rainwater. In particular, $t_{e v}$ took $24.6 \mathrm{~s}$ in Case P12Q1 to reach the exit from the center of Sec. A, while it required $19.9 \mathrm{~s}$ to evacuate from the center of Sec. C. These results indicate that the average walking speed in Sec. A decreased to $21.9 \mathrm{~m} / \mathrm{min}$, which is about $36 \%$ of the normal walking speed of a male $(60 \mathrm{~m} / \mathrm{min})$. Thus, a drainage system is required at the point where the incoming flows collide with each other to mitigate undesirable inundation depth increase.

Evacuation safety should be also considered to secure the safety of citizens from floods in underground spaces. In this study, evacuation safety was evaluated using the specific force $\left(M_{0}\right)$ shown in Equation (2) according to rainwater inflow conditions. Figure 13 shows the distributions of $M_{0}$, and the time-averaged flow velocity in Sec. A, where the flow velocity increased due to rainwater inflow. In Case P1Q1, rainwater propagated from P1 to an ambient space and the velocity gradually decreased in the right side due to loss of inertial force. Thus, the rainwater was pushed out to the right side of Sec. A, and the inundation depth increased simultaneously, as shown in Figure 9a. As aforementioned in Section 2.1, $M_{0}$ needed to be maintained at less than 0.125 for safe evacuation [1]. However, in Case P1Q1, $M_{0}$ increased to 0.19 near the center of Sec. A due to an increase in both the inundation depth and the flow velocity. The velocity distributions in Cases P123Q1 and P1234Q1 showed different patterns than for Case P1Q1. In these cases, the inflowing water from P1 and P2 collided near the center of Sec. A, and the velocity abruptly decreased in the same time that the inundation depth increased. As shown in Figure 13c, the velocity on the right side decreased compared to Case P123Q1 because the flow added in P4 weakened the flow heading to Sec. B. Nevertheless, 
$M_{0}$ was in the range of $0.13-0.22$ on the left side of Sec. A due to increase of the inundation depth, whereas $M_{0}$ in Case P123Q1 was less than 0.125.

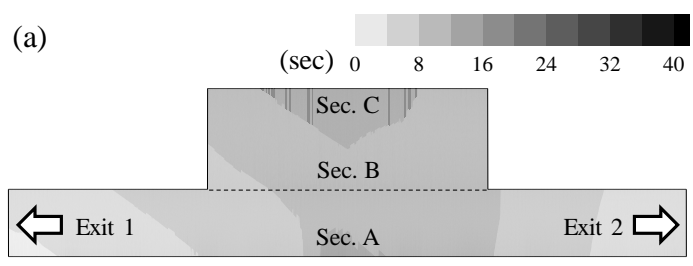

(c)

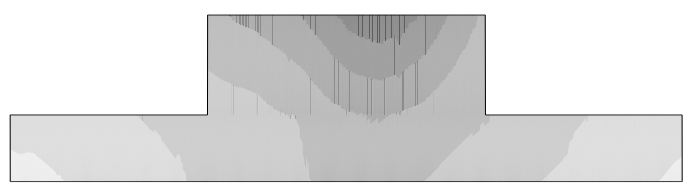

(e)

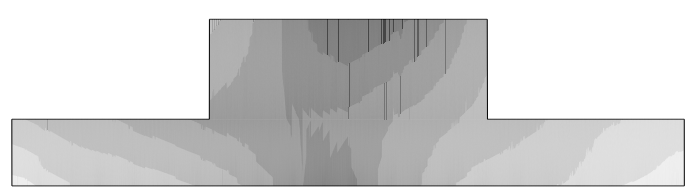

(b)

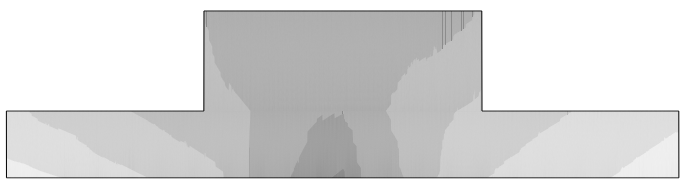

(d)

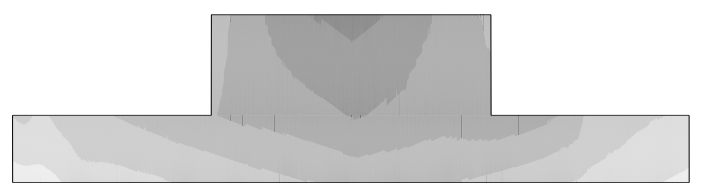

(f)

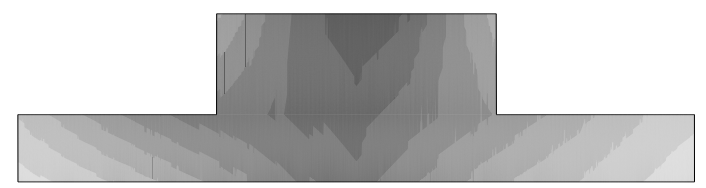

Figure 12. Spatial distributions of the underground evacuation time: (a) Case P1Q1; (b) Case P12Q1; (c) Case P13Q1; (d) Case P14Q1; (e) Case P123Q1; (f) Case P1234Q1.

The comparisons between Case P1Q1 and Case P123Q1 show that the evacuation safety could be worse according to flow velocity even though the inundation depth in Case P1Q1 was lower than in Case P123Q1. Thus, in the areas where $M_{0}$ increased up to 0.125 due to flow velocity, safety handles are necessary to prevent falling from the flow. Furthermore, if the value of $M_{0}$ increases due to the inundation depth, as in Case 1234Q1, a drainage system is necessary to increase evacuation speed.

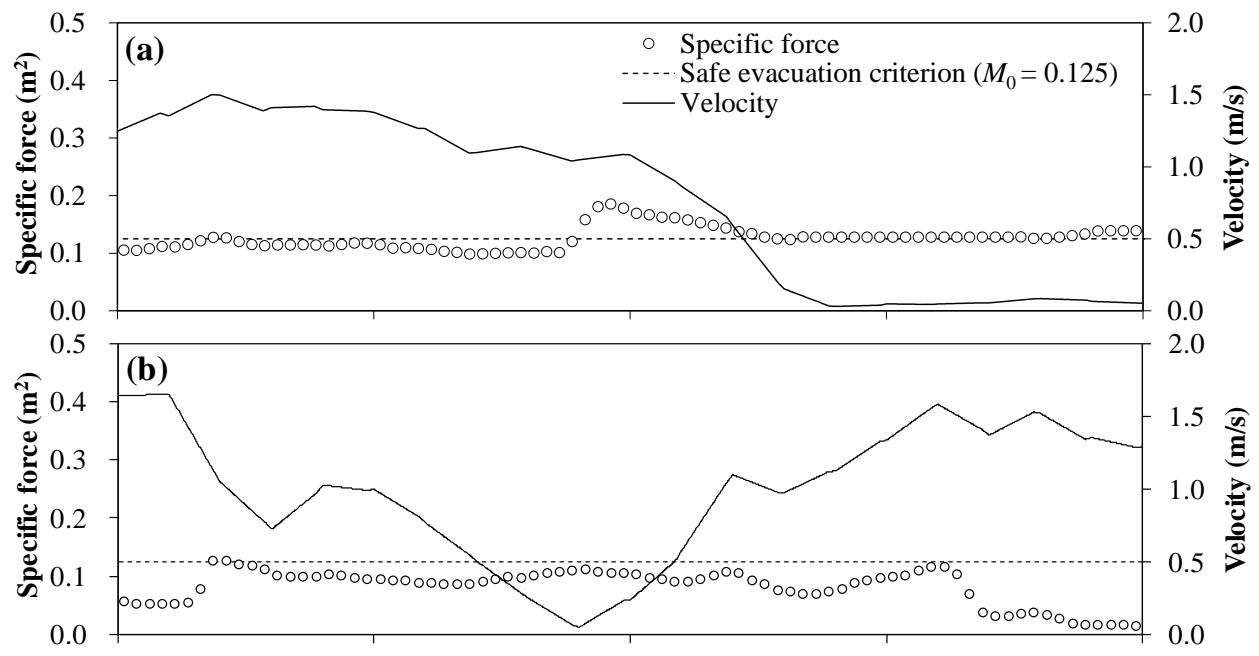

Figure 13. Cont. 


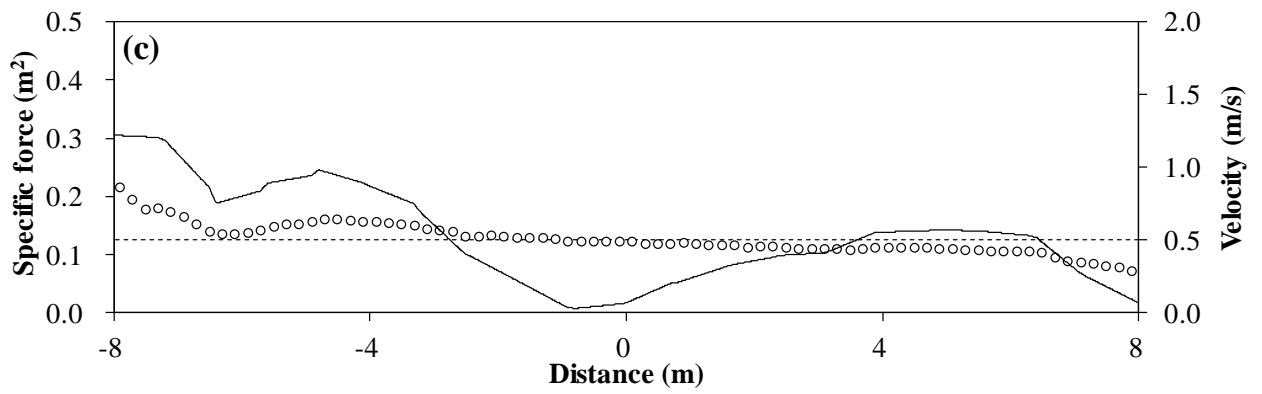

Figure 13. Changes of the specific force and the velocity in Sec. A: (a) Case P1Q1; (b) Case P123Q1; (c) Case P1234Q1.

\section{Concluding Remarks}

In this study, water depth was calculated using a non-contact image analysis method to measure the inundation depth inside an underground space. To calculate the inundation depth through image analysis, a laser sheet was formed on the water surface and light-reflecting floating particles were introduced on the water surface so that the water surface could be clearly observed. After that, orthographic images of measurement sections were taken using a digital camera to calculate the inundation depth. From a number of captured images, a representative image, which showed mean motion of inundation, was obtained using the time-average method. From the pixel values of the representative image, the position where the local minimum pixel value was first obtained was set as the water surface. A comparison of the inundation depth calculated using the laser image analysis method with the method using a digital point gauge revealed that the error in calculation results ranged from $2.97 \%$ to $7.67 \%$, indicating that the laser image analysis method produced relatively accurate results. The laser image analysis method is applicable in model experiments, in which a laser sheet can cover a measurement section and the contact type measurement apparatus is not applicable due to shallow water depth. However, the proposed method has limitations that the method can be applied in the small-scale model, which allows for the formation of a laser sheet. Thus, in a future study, it is required to improve the use of a laser sheet, which is necessary to visualize a boundary between the water and the air, for widening applicability.

Experiments were performed for cases when the positions and number of rainwater inflow points were varied or when non-uniform flow rates were introduced to simulate various situations for rainwater inflow. The inundation depth rise section changed when rainwater inflow positions and flowrate were varied. From the inundation depth measurements, the time required for evacuation in the subway station and evacuation safety were analyzed. The spatial distributions of evacuation time showed that more time can be required for evacuation due to collision of inflowing rainwater even though distance to the exit is shorter than other positions. Thus, a drainage system is required to decrease inundation depth in areas where inflowing water collides. Furthermore, the calculation results of the specific force show that evacuation safety can be worse where the flow velocity increases, even though the inundation depth is lower. In these areas, safety handles are necessary to prevent falling down due to the flow. The calculation results of evacuation time and the evacuation safety shown in this study were considered for evacuating a person, and in the future study, it is necessary to consider population to establish an evacuation plan.

Author Contributions: I.P., H.S., Y.R., and D.S.R. designed study concept and experiments; I.P. and H.S. performed the experiments; I.P., Y.R., and D.S.R. analyzed the data; I.P., Y.R., and D.S.R. wrote the paper.

Funding: This study was supported by a grant from Strategic Research Project (Smart Flood Management) funded by the Korea Institute of Civil Engineering and Building Technology.

Conflicts of Interest: The authors declare no conflict of interest. 


\section{References}

1. Ishigaki, T.; Asai, Y.; Nakahaata, Y.; Shimada, H.; Baba, Y.; Toda, K. Evacuation of aged persons from underground space. Water Sci. Technol. 2010, 62, 1807-1812. [CrossRef] [PubMed]

2. Shao, W. Critical rainfall intensity for safe evacuation from underground spaces with flood prevention measures. J. Zhejiang Univ. Sci. A 2010, 11, 668-676. [CrossRef]

3. Joo, J.; Kim, T.H. An experimental study on evacuation ability during underground space inundation. J. Korean Soc. Hazard Mitig. 2015, 15, 189-196. (In Korean) [CrossRef]

4. Kim, H.-J.; Rhee, D.S.; Song, C.G. Numerical computation of underground inundation in multiple layers using the adaptive transfer method. Water 2018, 10, 85. [CrossRef]

5. Takagi, Y.; Tsujikawa, A.; Takato, M.; Saito, T.; Kaida, M. Development of a noncontact liquid level measuring system using image processing. Water Sci. Technol. 1998, 37, 381-387. [CrossRef]

6. Nguyen, L.S.; Schaeli, B.; Sage, D.; Kayal, S.; Jeanbourquin, D.; Barry, D.A.; Rossi, L. Vision-based system for the control and measurement of wastewater flow rate in sewer systems. Water Sci. Technol. 2009, 60, 2281-2289. [CrossRef] [PubMed]

7. Kim, J.; Han, Y.; Hahn, H. Image-based water level measurement method adapting to ruler's surface condition. J. Korea Soc. Comput. Inf. 2010, 15, 67-76. (In Korean)

8. Kim, Y.; Park, H.; Lee, C.; Kim, D. Development of a cloud-based image water level gauge. IT Converg. Pract. 2014, 2, 22-29.

9. Zhang, D.; Li, C.; Wang, G. A new style ruler and supporting image detection algorithm for urban flood water level measurement. In Proceedings of the 2013 IAHR World Congress, Chengdu, China, 8-13 September 2013.

10. Aberle, J.; Rennie, C.; Admiraal, D.; Muste, M. Experimental Hydraulics: Methods, Instrumentation, Data Processing and Management: Volume II: Instrumentation and Measurement Techniques; CRC Press: Boca Raton, FL, USA, 2017.

11. Duan, J.; Tench, C.; Gottlob, I.; Proudlock, F.; Bai, L. Automated segmentation of retinal layers from optical coherence tomography images using geodesic distance. Pattern Recognit. 2017, 72, 158-175. [CrossRef]

12. Voulgaropoulos, V.; Angeli, P. Optical measurements in evolving dispersed pipe flows. Exp. Fluids 2017, 58, 170. [CrossRef]

13. Committee of Countermeasures against Inundation Disasters in Underground Spaces (CCIDUS). Guideline for Measures against Inundation of Underground Spaces; Ministry of Land, Infrastructure, Transport and Tourism (MLIT): Tokyo, Japan, 2002. (In Japanese)

14. Lee, C.J.; Seo, M.B.; Kim, D.G.; Kwon, S.I. A novel water surface detenction method based on correlation analysis for rectangular control area. J. Korea Water Resour. Assoc. 2012, 45, 1227-1241. (In Korean) [CrossRef]

15. Wang, H.; Pope, S.B. Time-averaging strategies in the finite-volum/particle hybrid algorithm for the joint PDF equation of turbuelnt reactive flows. Combust. Theory Model. 2008, 12, 529-544. [CrossRef]

16. Kim, H.; Lee, D.H.; Park, H.; Rhee, D.S.; Ryu, Y.; Park, M.; Kim, H.; Lee, K.-O.; Eom, J.-H.; Kim, M.; et al. Smart Flood Management; KICT 2017-179; Korea Institute of Civil Engineering and Building Technology (KICT): Goyang-si, Korea, 2017.

(C) 2018 by the authors. Licensee MDPI, Basel, Switzerland. This article is an open access article distributed under the terms and conditions of the Creative Commons Attribution (CC BY) license (http:// creativecommons.org/licenses/by/4.0/). 